\title{
A textura da justiça Sobre os limites do procedimentalismo contemporâneo
}

\author{
The fabric of justice \\ Limits of proceduralism
}

Axel Honneth*

Resumo: $\mathrm{O}$ texto tenta, num primeiro passo, mostrar que a textura intrínseca da justiça não consiste em bens distribuíveis, mas em relações sociais comumente aceitas que são constituídas por práticas perpassadas de conteúdo moral. Nessas práticas podem ser encontradas aquelas que definem o que significa tratar uma outra pessoa de forma razoável ou justa. Se este ponto de partida é convincente, então algumas consequências metodológicas sobre o conceito de justiça tem que ser tiradas e que são apresentados na segunda etapa: ao invés de construir um procedimento normativo que nos permite deduzir o conteúdo de justiça, temos de começar pela reconstrução das práticas sociais que nos informam sobre o respeito à justiça. O resultado será, tal como indicado em uma terceira etapa, a pluralização do nosso conceito de justiça, que inclui tanto princípios relevantes da justiça como há formas de relações sociais geralmente aceitas e apreciadas.

Palavras-chave: Reconhecimento; Teoria da justiça; Procedimentalismo; Filosofia política

\begin{abstract}
The lecture tries, in a first step, to show that the intrinsic fabric of justice doesn 't consist of distributable goods, but of commonly accepted social relations which are composed of morally loaded practices; in these practices those regards can be found which define what it means to treat another person in a fair or just manner. If this starting point is convincing, then some methodological consequences concerning the concept of justice have to be drawn which are presented in the second step: Instead of constructing a normative procedure which allows us to deduce the content of justice, we
\end{abstract}

* Conferência apresentada no $4^{\circ}$ Simpósio Internacional sobre Justiça. Porto Alegre, 29 set. $-1^{\circ}$ out. 2009. Uma versão anterior havia sido apresentada em Munique, em dez. 2008, na SiemensStiftung, a convite de Heinrich Meier e sob moderação de Jürgen Habermas. Axel Honneth é doutor e livre-docente em Filosofia, professor na Universidade de Frankfurt e diretor do Instituto para Pesquisa Social. Principais publicações: Luta por reconhecimento (Editora 34), Verdinglichung (Suhrkamp), Sofrimento de indeterminação (Esfera Pública). Este texto, ainda inédito, foi gentilmente cedido para publicação na Civitas pelo autor e pela Editora Suhrkamp. Tradução do alemão: Emil A. Sobottka e Joana Cavedon Ripoll. honneth@uni-frankfurt-de

\begin{tabular}{|l|l|l|l|l|l|}
\hline Civitas & Porto Alegre & v. 9 & n. 3 & p. 345-368 & set.-dez. 2009 \\
\hline
\end{tabular}


have to start by reconstructing the social practices which inform us about the respects of justice. The result will be, as indicated in a third step, a pluralization of our concept of justice which includes as many relevant principles of justice as there are commonly accepted and appreciated forms of social relations.

Keywords: Recognition; Theory of justice; Proceduralism; Political Philosophy

Depois que o debate sobre a relação entre liberalismo e comunitarismo se extinguiu com a mesma rapidez com que ele surgiu há duas décadas, parece que o abismo entre a teoria filosófica e a práxis política parece estar se aprofundando novamente. Naquela época, quando os escritos de Michael Walzer, John Rawls e Charles Taylor eram amplamente discutidos na esfera pública intelectual (Honneth, 1992b), cabia à filosofia política manifestamente fornecer ideias teóricas e pontos de referência para a práxis política; em todo o caso, por um breve momento poderia parecer que os esforços filosóficos em busca de um conceito apropriado de justiça seriam pertinentes para a negociação política de objetivos e programas. ${ }^{1}$ Hoje, depois de o desafio do comunitarismo ter se desvanecido, começa a se alastrar novamente o antigo mal-estar de um paralelismo da filosofia política com o agir político, de teoria e práxis. Entrementes poderia existir um consenso geral de que sociedades democráticas estão embasadas em fundamentos normativos que exigem a garantia jurídica da autonomia individual de todos os cidadãos e todas as cidadãs; também parece haver amplo apoio para a exigência seguinte, segundo a qual estes princípios de igualdade jurídica e política pedem uma redistribuição econômica que permita aos mais desfavorecidos que eles façam uso efetivo dos seus direitos garantidos pelo estado. Mas estes princípios gerais de justiça social são destituídos de valor informacional para a práxis dos representantes políticos ou dos movimentos sociais; quando está em questão a solução de problemas complexos, como aqueles desafios relacionados com a reestruturação do estado de bem-estar social, os princípios fundamentais amplamente aceitos rapidamente perdem seu efeito esclarecedor e orientador. $\mathrm{O}$ abismo que se abriu com isso não é o de um descompasso temporal entre a fundamentação filosófica e a aplicação prática; não se configura a situação em que custaria somente esforço, tempo e persistência para transformar os princípios de justiça desenvolvidos teoricamente em diretrizes da ação política. Antes, parece que

Essa aplicabilidade política fica mais evidente nas discussões em torno dos escritos programáticos de Amitai Etzioni (1998). Para a discussão política na Alemanha, vd. Zahlmann (1992). 
os princípios normativos em geral foram formulados num nível tal, que se torna impossível derivar deles orientação para a ação política; constantemente parece necessário recorrer a outras normas filosóficas adicionais, ainda não fundamentadas, antes que se descortine a perspectiva de uma solução "justa" (Miller, 2008, cap. 1).

Nessa situação de um crescente abismo entre teoria filosófica da justiça e práxis política parece razoável dar-se um passo atrás, para observar de uma maior distância o primeiro dos dois lados mencionados; pois é perfeitamente possível que tenham sido as próprias deficiências conceituais ou categoriais dos esforços teóricos que levaram a um aumento da distância em relação à política. Por conseguinte, no que segue pretendo tentar desligar-me passo a passo do universo de premissas da teoria da justiça liberal predominante, para poder assumir uma perspectiva externa que me permita seu exame crítico. Quero proceder de tal modo que, num primeiro passo, destaque três elementos que hoje parecem fazer parte de um consenso abrangente de praticamente todas as teorias da justiça; sem levar em consideração as muitas diferenças entre as teorias individuais, afirmarei que um esquema procedimentalista fundamental, a ideia da justiça distributiva e uma certa fixação no estado em conjunto formam a base teórica das mais recentes teorias da justiça (1). Em um segundo passo, quero submeter consecutivamente cada um destes pilares a um exame e questioná-los; começarei com o paradigma da distribuição porque em minha visão ele contém a chave para a crítica também dos outros dois componentes teóricos (2). Somente depois de ter desvelado todos os três elementos como questionáveis posso começar a esboçar os contornos de um modelo normativo alternativo; este terceiro passo novamente será iniciado a partir do elemento central, a saber, pela pergunta sobre como efetivamente devemos imaginar a matéria da justiça social se a ideia da distribuição de bens não representa a sua solução adequada; a partir daqui esboçarei então também a resposta às duas outras perguntas que surgiram com o fato de que nem o esquema fundamental procedimentalista nem a fixação no estado possam seguir servindo como respostas satisfatórias (3). Somente bem no final indicarei as consequências que resultam da recomposição almejada da teoria da justiça; aqui retornarei ao meu ponto de partida, a saber, à relação entre teoria filosófica da justiça e práxis política. Já deve ter ficado claro que o fio condutor de todo meu modo de proceder é formado pela discussão da questão sobre como devemos imaginar-nos a textura ou a matéria da justiça social. 
Na empresa filosófica hoje parece haver um amplo consenso em relação à questão sobre como devem estar constituídas as premissas de uma teoria da justiça social; se bem que aqui e acolá ainda haja alguma resistência com relação a elementos isolados de uma tal concepção geral de justiça, de um modo geral há sim concordância sobre o processo de sua fundamentação e o âmbito de seu objeto central. Tanto a justificação como a determinação conteudística da justiça devem resultar da ideia geral de que os princípios de justiça sejam expressão da vontade comum de todas as cidadãs e todos os cidadãos de asseguraremse reciprocamente as mesmas liberdades subjetivas de ação. Mesmo que este princípio abstrato pareça uma unidade homogênea, confluem nele dois complexos imaginários que advêm de diferentes determinações de liberdade: de um lado, aquilo que é denominado justiça social deve ser avaliado com base na garantia de autonomia pessoal, concebida como puramente individual, mas, de outro, os princípios de justiça correspondentes devem ser passíveis de ser concebidos como resultado de uma formação comum da vontade, tal como ela só acontece na cooperação entre sujeitos. ${ }^{2}$ Quero denominar componente "material" o primeiro elemento desta construção, aquele no qual se trata da garantia igual da autonomia individual, e, em contrapartida, designar princípio de forma o segundo, no qual se trata do modo de geração de princípios de justiça.

Na componente material da mencionada construção da justiça efetiva-se o fato de que a sociedade liberal, desde o princípio, compreende como uma de suas conquistas essenciais os esforços para libertar os indivíduos da tutela externa e de dependências pessoais: a liberdade individual sob condições de modernidade deve ser mensurada no desdobramento imperturbado de objetivos subjetivamente elegidos, assegurado em princípio igualmente a cada um. Com essa nova compreensão de liberdade modifica-se substancialmente aquilo que é concebido como tarefa material da justiça: enquanto anteriormente ela servia sobretudo para garantir a cada um uma posição adequada e uma subsistência correspondente segundo uma ordem de status dada, ela agora deve garantir a todos os sujeitos igualmente um espaço para a perseguição de preferências individuais. Na formulação aparentemente inocente, porém, logo se revela um componente sobressalente de sentido, que tem um papel central para a compreensão atual de justiça; segundo ele, a liberdade do indivíduo deve ser tanto maior, quanto menores forem as limitações por parte de outros, quanto

2 Uma boa visão panorâmica sobre esta tensão inerente às teorias modernas da justiça é dada por Ladwig (2004); cf. também Wellmer (1993). 
mais independente ele seja, portanto, de todos os parceiros de interação. Certamente que este isolamento do sujeito frente a relações intersubjetivas não decorre automaticamente da ênfase liberal na individualidade da liberdade; mas nas imagens que apóiam o novo modelo imaginário, nos exemplos que o permitem ter impacto público, a ideia segundo a qual os vínculos sociais em geral devam ser tidos como limitações da liberdade individual conquista terreno. Pelos caminhos que com isso estão predefinidos, penetra também nas modernas teorias da justiça um conceito individualisticamente reduzido de autonomia pessoal; aqui, pois, surge a ideia transcendente de que a criação de relações sociais justas deva servir primeiramente à finalidade de possibilitar a todos sujeitos igualmente uma forma de autodeterminação que os permita ser tão independentes de seus parceiros de interação quanto possível. ${ }^{3}$ A consequência mais importante da unilateralização assim esboçada é o surgimento do esquema de pensamento que pode ser definido como "paradigma da distribuição": pelo fato de que toda dependência de outros é vista como uma ameaça à liberdade individual, essa só pode ser assegurada se cada indivíduo dispõe em suficiência sobre meios geralmente valorizados, para poder realizar seus próprios planos de vida. Por conseguinte, a tarefa material da justiça consiste em assegurar algum tipo de distribuição deste tipo de "bens", de tal modo que permita a todos os membros da sociedade igualmente a perseguição de suas preferências individuais. Ao final do processo de desenvolvimento esboçado, consequentemente, justiça é equiparada a "justiça distributiva", sem que sequer se questione se liberdade individual efetivamente pode ser compreendida essencialmente segundo o modelo da utilização ou da fruição de bens. ${ }^{4}$

Mas antes de discorrer sobre as deficiências do paradigma distributivo, os outros componentes da atual concepção de justiça devem ser detalhados. Já havia ficado claro que na determinação geral da justiça social hoje subsiste uma certa tensão na medida em que ao lado da liberdade concebida individualisticamente também é reivindicado um elemento da cooperação voluntária entre os sujeitos; a saber, no detalhamento do procedimento por meio do qual devemos poder conceber determinações justificadas dos princípios correspondentes de distribuição aponta-se regularmente para a formação comum da vontade de todas as cidadãs e todos os cidadãos, cujo resultado deve poder ser pensado como sendo o assentamento daqueles princípios normativos. Este princípio

3 Para a crítica desta concepção individualista ou privatista da liberdade individual, cf. entre outros Taylor (1988), Raz (1986), Sandel (1982).

4 Uma crítica sistemática do esquema distributivo pelo que sei ainda está por ser feita; mas confira as observações em Young (1990, cap. 1) e Habermas (1996, p. 71ss). 
formal da recente teoria da justiça, que também pode ser concebido como seu procedimentalismo constitutivo, é resultado de uma reflexão que leva em conta a autonomia pressuposta dos sujeitos: porque os membros da sociedade devem em princípio poder ser concebidos como livres e autodeterminados, a concepção de justiça não pode pretender fixar a sua revelia como deve ser feita em detalhes uma distribuição equitativa dos bens; ao invés disso, finge-se em geral uma "situação original", o fechamento de um contrato ou uma situação de deliberação, cujas condições apartidárias no sentido de um experimento mental nos devem permitir chegar a conclusões justificadas sobre qual o tipo de distribuição de bens as cidadãs e os cidadãos prefeririam (cf. a formulação clássica de Rawls, 1979, cap. 3). Portanto, segundo esta concepção, a fixação dos princípios distributivos não é feita a partir da teoria, mas deixada para um acordo original que os próprios participantes teriam fechado numa deliberação imaginada como equitativa e justa; esta autolimitação que ali ocorre pode ser designada como procedimentalista na medida em que a concretização do esquema distributivo é conectada com a realização virtual de um procedimento que deve garantir a concordância de todos os afetados pelas especificações. No entanto, no interior deste tipo de procedimentalismo sempre há uma certa tensão, pois na determinação da "situação original" ou da situação deliberativa sempre devem poder ser projetadas condições de justiça sobre as quais os deliberantes ainda devem vir a concordar; pois naquela situação inicial os partidos já devem poder deliberar entre si como livres e iguais para poder constituir uma decisão amplamente aceitável, de modo que ainda antes de suas deliberações uma parte das condições de liberdade ainda por serem esclarecidas já deve estar fixada. De certo modo, a teoria, bem ao contrário de sua intenção explícita, precisa antecipar os resultados normativos do procedimento e caracterizar já por si só as condições de autonomia (Habermas, 1996, p. 69 ss); e em minha opinião esta tensão se agudiza ainda mais, quanto mais nos movemos em direção a compreender o procedimento gerador de justiça não mais como um experimento mental, mas como um fenômeno no mundo social. $^{5}$

Mas também aqui quero proceder de tal modo que coloque em segundo plano os questionamentos indicados até que tenha esboçado também o terceiro elemento constitutivo das teorias da justiça hoje predominantes. Este elemento

\footnotetext{
Assim entendo a intenção fundamental de Jürgen Habermas (1992) em sua teoria da justiça desenvolvida em Facticidade e validade, que compreende os princípios do moderno estado de direito como condições institucionalizadas de possibilidade de um processo democrático da autolegislação pública. Mais tarde designarei esta intenção como "procedimentalismo historicamente situado".
} 
resulta como resposta à pergunta sobre qual agência ou quais instâncias são concebidas como apropriadas para implementar na realidade social os princípios distributivos tidos como justificados. $\mathrm{O}$ espectro das possibilidades neste caso vai da atribuição de toda a responsabilidade às instituições estatais até a concepção de que cada indivíduo deve possuir ele próprio a disposição para a aplicação dos princípios correspondentes. Mesmo que nem sempre esteja claro se as atuais teorias da justiça também querem incluir instâncias não-estatais ou comportamento individual em suas reflexões, suas ponderações fundamentais são marcadas pela ideia de que somente o estado democrático de direito representa a agência correspondente de efetivação da justiça. Esta tendência de concentrar todo poder de estruturação normativa no estado resulta de uma combinação de duas reflexões que, ambas tomadas por si, parecem plausíveis: de um lado, não se deve atribuir aos próprios membros da sociedade a responsabilidade pela justiça, pois essa atribuição viria acompanhada do risco de uma ditadura das virtudes, de uma exigência de comportamento moralmente exemplar, e ao mesmo tempo só o estado de direito deve dispor dos meios legítimos para impor efetivamente as medidas necessárias para a redistribuição dentro das diversas instituições básicas da sociedade. Nesse sentido, as teorias da justiça geralmente operam com o pressuposto de uma divisão moral do trabalho segundo a qual cidadãs e cidadãos devem produzir por si sós os respectivos princípios de justiça, cuja implementação então é vista como atribuição exclusiva do estado de direito democraticamente controlado. ${ }^{6} \mathrm{O}$ perigo de tal centralização estatal consiste manifestamente no fato de que tudo o que estiver fora do alcance do poder legal plasmador do estado surpreendentemente deve ficar inatingido pelas exigências de justiça: esferas sociais tais como famílias ou empresas privadas, que por boas razões só limitadamente podem ser influenciadas pelo direito, não podem ser utilizadas para nem responsabilizadas por tarefas da realização da justiça. Também a este ponto voltarei quando agora no próximo passo submeter as três componentes mencionadas a uma análise mais precisa.

Até agora nada mais fiz que esboçar algumas das premissas teóricas que em minha visão são amplamente partilhadas pelas concepções de justiça

6 Com uma intenção bem distinta, a saber a de uma crítica das concepções exageradas de justiça global, Thomas Nagel (2005) demonstrou como nas teorias liberais da justiça todo o poder formador de justiça é fixado no estado democrático de direito. 
hoje predominantes. Ainda que seguramente com significativas diferenças no detalhe, estas teorias definem a possibilidade de autonomia individual para cada indivíduo como essência da justiça na modernidade: a autonomia assim colocada em destaque deve ser assegurada e garantida ao disponibilizar-se para todas as cidadãs e todos os cidadãos aqueles bens básicos que são necessários para a realização de planos de vida individuais; mas os princípios segundo os quais estes bens devam ser distribuídos de forma justa não deverão ser fixados pela própria teoria, mas pelo círculo dos afetados. Para possibilitar isso, é idealizado um procedimento que, na forma de um experimento mental ou de um procedimento real, nos informe a que princípios distributivos os participantes chegariam nas condições da imparcialidade e da deliberação livre; e finalmente como agência a quem estes autores confiam a realização prática de suas regras é apresentado o estado de direito que providencia a realização correspondente por meio do direito legítimo. Por certo que muita coisa depende das determinações concretas que serão feitas nos diversos estágios; se os bens básicos são compreendidos apenas como recursos materiais ou também no sentido de determinados direitos de disposição, como são fixadas em detalhe as condições da imparcialidade e segundo qual modelo as atividades do estado são descritas, tudo isso muda substancialmente o recorte normativo de tais teorias da justiça. Mas, como mencionado acima, não estou aqui interessado em versões específicas dessas teorias, mas no quadro geral que a uma certa distância se obtém delas. Em primeiro lugar, salta aos olhos que quase sempre bens amplamente estimados são vistos como o material da justiça e que devem ser distribuídos entre as cidadãs e os cidadãos segundo critérios ainda por definir; nisso está pressuposto sempre um consenso entre os afetados de que todos eles, por si próprios, terão interesse em tais recursos generalizados, que são tidos como necessários para a criação e realização de planos de vida autônomos, propriamente elegidos (cf. novamente Rawls, 1979, p. 11ss; 1988, cap. $5, \S 4)$. Nesse sentido e tomada tal perspectiva como ponto de partida, a pergunta por uma ordem social justa nessas teorias só pode colocar-se como a pergunta pela distribuição justa de bens básicos.

Num primeiro olhar, a decisão preliminar assim tomada também parece como sendo evidente, pois parece que nós devemos uma parte importante de nossa liberdade individual simplesmente à circunstância de dispor sobre chances e meios para a realização de objetivos propriamente escolhidos: recursos financeiros abrem-nos uma variedade de opções em nossa vida, um espectro amplo de ofertas de trabalho nos permite a realização determinada de nossas habilidades. Mas já nessas formulações está quase imperceptivelmente pressuposto algo que não pode ser simplesmente assimilado no esquema 
significativo de distribuição de bens: para poder perceber a disposição sobre dinheiro como chance de liberdade, numa pessoa precisam estar formadas primeiro concepções sobre objetivos dignos de serem almejados, para poder compreender chances profissionais como caminhos para a realização das habilidades individuais, a pessoa primeiro precisa ter compreendido suas disposições e talentos como importantes e dignos de realização. Nenhum destes pressupostos necessários possui a forma de um bem fixo, eles não podem ser simplesmente "possuídos" como "coisas", mas precisam ser penosamente adquiridos em e através de relações entre pessoas. Não quero deixar valer já estes exemplos aleatórios como contestações, mas apenas utilizá-los como uma chave para encontrar um acesso a uma crítica do esquema distributivo como um todo.

O elo entre as duas últimas considerações consistia na ideia de que bens a rigor só podem ser considerados como meios significativos para a realização de liberdade individual se a pessoa interessada já for pressuposta como "autônoma"; pois aquilo que significa perceber recursos financeiros ou chances profissionais como possibilidades de liberdade não se deduz através do significado de tais bens, mas unicamente a partir da respectiva relação com eles. Por isso nem mesmo uma ampla e bem refletida lista de bens básicos pode informar sobre o que significaria conceder aos sujeitos condições para a autonomia pessoal; aquilo que efetivamente está em questão sempre se moveria antes do limiar daquilo que poderia ser encontrado explicitado em uma tal lista. Mais tardar a partir de Kant, mas provavelmente já a partir de Rousseau, denominamos como "autonomia" uma determinada espécie de autorrelação, que permite confiar em suas próprias necessidades, responsabilizar-se pelas próprias convicções e perceber as próprias habilidades como valiosas; ainda que estas formas de autoestima possam ser articuladas e expostas com o auxílio de bens, elas não podem ser adquiridas e mantidas por esse meio. ${ }^{7}$ Ao contrário, alcançamos a autonomia por vias intersubjetivas, a saber, ao aprendermos, através do reconhecimento por outras pessoas, a nos compreender como seres cujas necessidades, convicções e habilidades são dignas de serem realizadas; isso, por seu turno, só compreendemos em nós se ao mesmo tempo o concedemos àquelas pessoas que nos reconhecem, porque

As duas perspectivas de Rousseau e Kant naturalmente diferem entre si pelo fato de que Rousseau conecta colocação da autoestima com o pressuposto de um reconhecimento recíproco ou de estima por outros (cf. o notável texto de Neuhouser, 2008), enquanto Kant considera a colocação correspondente como o resultado de uma submissão individual à lei da ética (Hahn, 2008 , p. 52ss). Aqui não vou aprofundar a subsequente história da teoria, que inicia com Fichte. 
devemos poder reconhecer, como em um espelho, nosso próprio valor no comportamento delas com relação a nós. Nesse sentido, para poder surgir e se desenvolver, a autonomia necessita do reconhecimento recíproco entre sujeitos; nós não a adquirimos sozinhos, através de nós mesmos, mas unicamente na relação com outras pessoas que estejam igualmente dispostas a valorizar-nos da mesma maneira como nós devemos poder valorizá-las (Honneth, 1992a; Mackenzie e Stoljar, 2000; Meyers, 1989; Benson, 2005). ${ }^{8}$

Se contudo não forem bens quaisquer, mas tão somente estas relações de reciprocidade que representem condições da autonomia, então as atuais teorias da justiça erram de modo fundamental desde o início a estrutura de seu objeto. O paradigma distributivo com o qual elas operam dá origem à sugestão de que aquilo que deve tornar igualmente possível a autonomia poderia ser de algum modo distribuído segundo determinados princípios; nisso está pressuposto que este "material" da justiça encontra-se sempre já em um estado preparado, concreto, e que, além disso, pode ser acumulado individualmente pelos respectivos sujeitos. Mas ambas condições são impossíveis se nós só alcançamos a autonomia pela via do reconhecimento recíproco; pois tais relações jamais poderão estar tão concluídas e fixadas como bens o exigem, tampouco podemos de alguma maneira consumi-las ou desfrutar delas individualmente, pois elas necessitam sempre da cooperação de outros sujeitos. Autonomia é uma dimensão relacional, intersubjetiva, não uma conquista monológica; aquilo que nos ajuda a adquirir uma tal autonomia resulta de outra matéria que não aquela de que consiste um bem a ser distribuído; ela se compõe de relações vivas de reconhecimento recíproco que são justas na medida em que através delas e dentro delas aprendemos a valorizar reciprocamente nossas necessidades, conviçcões e habilidades. Naturalmente podemos designar também estas intersubjetividades práticas em sentido aristotélico como "bens", mas então não podemos subrepticiamente

8 Aqui naturalmente é importante mencionar que Rawls desde o início introduziu "as bases sociais da autoestima" como um bem básico, sim, como "talvez o mais importante bem básico" (Rawls, 1979, p. 479). Possivelmente devido às dificuldades já referidas de se considerar as condições da autoestima como um "bem" a ser distribuído (Doppelt, 1981), mais tarde em Liberalismo político consta que determinados outros bens básicos (ao lado de "direitos e liberdades fundamentais iguais" são mencionadas também "igualdade de chances equitativas") fazem parte "das bases sociais da autoestima" (Rawls, 1998, p. 160), elas próprias, portanto, não são mais tratadas como um bem básico. Para mim, nesses deslocamentos conceituais se revelam as dificuldades, impossíveis de serem solucionadas dentro do paradigma distributivo, para tornar as próprias relações intersubjetivas e as relações de reconhecimento como objeto de uma teoria liberal da justiça. Não obstante, tanto aqui como em outras passagens só se pode admirar a seriedade intelectual com que Rawls trata um problema claramente percebido por ele. 
atribuir-lhes aquele sentido econômico que resulta quando temos em mente o esquema da distribuição. ${ }^{9}$

Com estas contestações por ora só foi abalado o primeiro pilar básico das teorias da justiça hoje vigentes. O paradigma de distribuição, que elas tomam por base, revelou-se inadequado para determinar o material da justiça na modernidade: ao invés de falar de "bens", deveríamos falar de relações de reconhecimento, ao invés de pensar em "distribuição", deveríamos pensar em outros modelos para assegurar a justiça. Antes que eu possa aprofundar esse tema, necessito esclarecer se a partir da inversão da polaridade também resultam consequências para as outras duas componentes das teorias aqui em questão: é possível seguir com o procedimentalismo almejado e com o centramento na atividade estatal se como matéria prima da justiça não forem mais concebidos bens distribuíveis, mas relações intersubjetivas de reciprocidade?

O procedimentalismo, como vimos, vive da concepção de que seria falso deixar para a teoria a decisão sobre os princípios (distributivos) justos: antes pelo contrário, porque os sujeitos já necessitam ser pressupostos como parcialmente autônomos, eles próprios ou seus representantes devem ser simulados, na forma de um experimento mental, como aqueles autores que, sob condições equitativas e imparciais, conseguem, eles mesmos, tomar decisões sobre aqueles princípios. Mas independentemente de como se analise tal construção, nela sempre será necessário partir do pressuposto de que os (fictícios) atores deliberantes podem dispor livremente do material de suas decisões: aquilo que está por ser regrado, aquilo sobre o que as decisões imparciais deverão ser encontradas, precisa poder ser concebido como uma massa arbitrariamente moldável, pois do contrário o espaço para decisões estaria seriamente limitado por condições externas e estranhas. Neste exato ponto o procedimentalismo, hoje preferido, está preso de forma imanente ao pressuposto do paradigma distributivo; pois só faz sentido considerar a fixação dos princípios de justiça como resultado de um procedimento equitativo se ao mesmo tempo for pressuposto que os sujeitos deliberantes podem decidir tanto sobre aquilo a que se refere a decisão tão livre e ilimitadamente como sobre bens passíveis de serem arbitrariamente deslocados de um lado a outro. Para que seja preservada a ficção de uma geração autônoma de princípios justos,

9 Aos bens designados por Aristóteles como "éticos" falta a extensão física, que foi quem a rigor permitiu surgir a ideia de "reparti-los" segundo determinados princípios para permitir que mais pessoas ou todos pudessem passar a desfrutá-los. A equiparação subliminar dos bens éticos com objetos materiais que permitem uma repartição mereceria uma investigação específica. Substitutivamente, cf. Scheler (1966, p. 110ss) e Taylor (1985). 
no procedimentalismo o material da justiça necessita ser pensado segundo o modelo de uma matéria disponível: precisamos imaginar aquilo sobre o que queremos tomar decisões justificadas normativamente como uma massa que podemos subdividir em determinadas porções, para entregá-las aos sujeitos ou grupos que a elas têm direito. Nesse sentido, a ideia da distribuição de bens se constitui no pressuposto perfeitamente adequado para este tipo de procedimentalismo. Mas se esta premissa não se sustenta, se não pudermos mais pensar o material da justiça na forma de bens aleatoriamente subdivisíveis, mas se o pensarmos como relações sociais recíprocas, então as condições contextuais do procedimentalismo não deixam de ser afetadas; pois de repente não podemos mais desenhar-nos os atores deliberantes como colocados perante algo sobre o que possam dispor livremente e tão somente segundo suas próprias conviçcões de justiça. As relações de reconhecimento, que pelo até aqui dito se revelaram como as condições decisivas da autonomia pessoal, não formam uma espécie de matéria, acessível a uma alocação aleatória; em relação a elas, não podemos nos colocar no papel de tomadores de decisão que queiram deliberar sobre sua organização ou até mesmo sua distribuição justa como numa prancheta. ${ }^{10}$ Antes, aquelas relações de reconhecimento consistem em poderes desenvolvidos historicamente, que já sempre incidem sobre nós à revelia; querer livrar-se delas para poder ao mesmo tempo observá-las como um todo se revela uma ilusão tão vazia e ociosa como a pretensão de estruturálas e distribuí-las arbitrariamente.

Com isso, parece-me, o segundo pilar das teorias da justiça hoje vigentes também desmoronou. Tão logo não subsistam mais bens distribuíveis como matéria da justiça, tão logo por conseguinte nos despeçamos do paradigma distributivo, também não poderemos mais conceber a geração dos princípios de justiça correspondentes na forma de um procedimento fictício em uma situação original qualquer: por mais equitativa, imparcial e livre de dominação

${ }_{10}$ Numa discussão comigo Antony Laden defendeu a tese segundo a qual Rawls, em sua diferenciação entre justiça "alocativa" e "distributiva" (Rawls, 1979, p. 109-110), poderia evitar a problemática aqui levantada; segundo esta posição, enquanto a justiça alocativa só dá conta de uma determinada distribuição de uma determinada quantidade de bens entre pessoas "com determinadas preferências e necessidades", deve-se entender por justiça distributiva um princípio normativo que fixa as regras sob as quais as pessoas cooperam entre si equitativamente e podem repartir entre si os bens produzidos por elas. Eu ainda não vejo como esta diferenciação deveria poder evitar a dificuldade apontada por mim (e por outros): se bem que seja verdade que Rawls conecta a "adequação da distribuição" com a "justiça nas relações sociais de cooperação", mas esta é compreendida no sentido de princípios que fixam "o que, quanto e como será produzido" e quem tem sobre isso quais "direitos justificados" (ibid.). O sentido material da justiça segue consistindo na distribuição de algo que é concebido como em princípio passível de ser "produzido". 
que tal procedimento sempre possa ser constituído virtualmente, com o desaparecimento do esquema distributivo as partes envolvidas perdem ao mesmo tempo a capacidade para conceber em si a questão de uma ordem social justa como questão de recursos ou meios livremente disponíveis. Da alternativa correspondente, segundo a qual este procedimento deve ser concebido como um acontecimento real, palpável, na esfera pública democrática, eu me ocuparei um pouco adiante; aqui quero voltar-me primeiro à questão acerca do que será da terceira componente das atuais teorias da justiça face à desmontagem até aqui feita.

Esse último pilar consistia no pressuposto de que somente o estado de direito dispunha dos meios adequados, geralmente aceitos, para implementar na sociedade os princípios de justiça tidos como justificados: por meio dos direitos protegidos por sanções, ele impõe de cima para baixo uma distribuição de bens básicos segundo o modelo que teria sido acordado anteriormente pelos atores sociais na deliberação fictícia. A interdependência entre este esquema de divisão de tarefas com o pressuposto do paradigma distributivo é tão evidente, que dificilmente ainda necessita de uma explicitação detalhada: a tarefa de realização da justiça precisa já aqui ser atribuída unicamente ao estado, pelo fato de só ele possuir, graças às suas múltiplas competências regulatórias, o poder de distribuir aqueles bens que parecem ser essencialmente decisivos para possibilitar igualmente a autonomia individual. Mas o que resta desta centralidade estatal tida como óbvia, se a ideia de uma justiça distributiva foi abandonada e substituída pela ideia de que são sobretudo relações comunicativas de reciprocidade que formam o terreno fértil e as condições de possibilidade para a autonomia individual? A primeira dificuldade que está colocada aqui resulta da circunstância de que devemos nossa autonomia hoje à inserção em diversas destas relações sociais, das quais cada qual pode ser tida como insubstituível; ao lado da comunidade democrática, na qual se exige de nós que nos reconheçamos reciprocamente como livres e iguais, seguramente pode-se contar entre elas também as relações familiares entrementes fortemente pluralizadas e as relações de trabalho precarizadas, nas quais parece que adquirimos por seu turno outras facetas de nossa autoestima (Honneth, 2003 , p. 201ss). Aqui, pelo menos por ora, não importam os detalhes de tal listagem, mas unicamente a circunstância de que exclusivamente uma destas formas de intersubjetividade prática é influenciável direta e imediatamente pela atividade do estado: pois somente a relação jurídica pode ser concebida como uma esfera social na qual o estado como uma agência de autolegislação democrática interfere de modo diretivo nas condições das relações de reconhecimento, ao modificar a abrangência dos direitos subjetivos, incluir 
novos grupos sociais ou declarar realidades modificadas como circunstâncias juridicamente relevantes. Aqui, pois, onde nos reconhecemos reciprocamente como cidadãos iguais e livres, e com isso alcançamos consciência de nossa autonomia política, segue fazendo sentido conceber a realização da justiça segundo o modelo de uma atividade direta do estado. Em contrapartida, as duas outras esferas de reconhecimento recíproco acima citadas são acessíveis a este tipo de influência legal estatal em grau muito limitado: nem nas relações familiares, nem nas relações sociais de trabalho o estado de direito pode intervir diretamente em favor de uma melhoria nas condições de reconhecimento se ele não quiser ferir os pressupostos próprios de sua existência. Por outro lado, parecem ser precisamente estas duas esferas de ação que têm uma importância especial para o fomento geral e amplo da autoestima individual: pois que nas famílias são colocadas as bases para a aquisição de tudo aquilo que mais tarde caracterizará nossa autoconfiança, nossa capacidade de articular necessidades (Honneth, 2000), e no intercâmbio social de desempenho podemos alcançar a capacidade não menos importante de nos perceber como valiosos, como socialmente úteis em nosso desempenho e nossas competências (Honneth, 2008a; Meyers, 1987) - ambos são componentes bem centrais e essenciais da capacidade de posicionar-se na esfera pública social "sem vergonha ou medo" (Adam Smith), portanto como autônomos. O que porém acontece se o estado democrático de direito dispuser apenas de meios muito limitados para intervir corretivamente nas relações de reconhecimento destas esferas? Precisamos abandonar o propósito de criar também aqui condições mais justas e que fomentem a autonomia apenas porque parecem não estar à nossa disposição outras agências de justiça que não o estado de direito?

Neste ponto difícil parece-me fazer sentido transferir também para o campo das teorias da justiça a descentralização do conceito de poder realizada a partir dos trabalhos de Michel Foucault nas últimas décadas. Enquanto até pouco tempo nas ciências políticas e na teoria social estava-se convencido de que a condução política se realizava sempre apenas de modo linear, de cima para baixo, através da atividade do estado, agora se sabe que não é assim, pois a manutenção do poder político é assegurada em boa medida através de uma rede ampla e descentralizada de organizações semiestatais e civis. Se agora tentamos tornar frutífera esta concepção também para a teoria da justiça, logo se revela que as propostas tradicionais padecem de uma concentração muito forte na atividade estatal; pois assim como a dominação política é reproduzida a partir de instâncias diversas e apenas desarticuladamente conectadas entre si, provavelmente também a justiça social, muito mais intensamente do que admitido no passado, é conquistada e assegurada por muitas agências 
atuantes em forma de rede e que se movem todas sobre o terreno préestatal da sociedade civil. As instituições que nos surgem diante dos olhos, tão logo o olhar é desviado das medidas do estado de direito, são, via de regra, organizações pré-estatais, associações ou sociedades que se engajam em favor de uma melhoria nas condições de reconhecimento em nome da justiça; precisamos apenas recordar-nos de grupos familiares de autoajuda, sindicatos, comunidades eclesiásticas ou outros agrupamentos civis para ter uma visão viva sobre a quantidade de lugares em nossa sociedade em que se encontram tais agências de realização da justiça. Um protótipo destas agências pré-estatais relevantes para a justiça poderiam constituir as corporações hegelianas (Hegel, 1970, § 250-256); também sua função para Hegel consiste sobretudo em tornar complementarmente efetivo o princípio moral de uma determinada esfera social, a saber, o da "sociedade burguesa" e em reforçá-lo através de medidas práticas junto a todos os participantes. ${ }^{11}$ Com certeza falta a estas organizações a força comprometedora e vinculante que dá às medidas legais do estado sua grande possibilidade de influência; frequentemente falta a elas também o vocabulário normativo para aclarar para si próprias seu papel específico em assegurar e fomentar autonomia individual; mas disto não se segue que estas redes pré-estatais permaneçam sem qualquer influência sobre as relações reais de interação que são responsáveis por assegurar e estender a justiça social. Nossa concepção de justiça, assim quero dizer, está fortemente restringida pela hoje usual fixação no estado; o fato de não conseguirmos perceber as atividades daquelas organizações civis como intervenções morais, como incentivadoras sociais de justiça, é consequência de um estreitamento do olhar a que as teorias da justiça hoje dominantes nos induzem.

As últimas observações devem ter mostrado que até aqui eu procedi essencialmente de um modo que talvez pudesse melhor ser designado como "terapêutico": era para ter sido evidenciado, apenas em forma negativa, que o quadro que as teorias atuais da justiça nos mostram leva a desconhecer sua real estrutura e modo de efetividade. De certo modo entendemos mal o lugar que a justiça ocupa em nossa prática cotidiana se tentamos compreendê-la segundo o esquema que nos é sugerido pelas teorias oficiais com seus modelos

11 A respeito do complexo das "corporações" em Hegel, cf. Schmidt am Busch (2002, p. 129ss). Outro exemplo para esta concepção descentralizada das instâncias formadoras da justiça eu vejo na ideia de Durkheim segundo a qual só se obtém a moral social em sociedades modernas através de toda uma rede de corporações relativamente autônomas e institucionalizadas, dotadas de funções formadoras de justiça (Durkheim, 1999). 
distributivos e seus ensinamentos sobre situação original. Na terceira e conclusiva parte de minha exposição quero passar a desenvolver, a partir das concepções alternativas apenas indiretamente sugeridas até aqui, os contornos de outra e, como quero crer, mais adequada concepção. Se tivesse que esboçar esta concepção em poucas palavras,assim diria: que primeiro o esquema distributivo teria que ser substituído pela concepção de uma inclusão de todos os sujeitos nas relações de reconhecimento desenvolvidas em cada situação; segundo, que no lugar da construção de um procedimento fictício deveria ser colocada uma reconstrução normativa que revele histórico-geneticamente as normas morais fundamentais daquelas relações de reconhecimento; e, terceiro, que o olhar exclusivo sobre a atividade reguladora do estado de direito deveria ser complementado por uma consideração descentralizada de agências e organizações não estatais. No que segue quero aclarar brevemente estes três passos.

Está claro que também o modelo visado deve tomar como ponto de partida a ideia normativa segundo a qual todos os membros de sociedades modernas devem poder dispor de maneira igualitária sobre as habilidades e condições para a autonomia individual; portanto, a diferença em relação às posições anteriormente discutidas não consiste num afastamento deste núcleo moral de nossa concepção atual de justiça, mas numa determinação totalmente distinta de suas implicações materiais. A questão chave aqui constitui-se na pergunta acerca do modelo segundo o qual devemos conceber a promoção social daquela autonomia sobre cujo lugar central ambas posições estão de acordo. Enquanto a liberdade em questão for compreendida como algo que cada indivíduo em princípio pode alcançar por si próprio, é suficiente assumir bens individualmente disponíveis como a matéria da justiça; com sua ajuda o indivíduo deverá ter condições de criar para si um espaço para a perseguição dos planos de vida por ele mesmo escolhidos, de forma que é tarefa da justiça social na modernidade providenciar o equipamento de cada indivíduo com tais bens de modo tão igualitário e suficiente quanto possível. Em contrapartida, na concepção que eu já apontei diversas vezes, a autonomia individual não é concebida como uma dimensão monológica, mas intersubjetiva: segundo ela, o indivíduo só alcança a liberdade da autodeterminação ao aprender, em relações de reconhecimento recíproco, a compreender suas necessidades, convicções e habilidades como algo que vale a pena ser articulado e perseguido na vida pública. Talvez já devesse ser mencionado aqui, que com isso a justiça distributiva não perderia totalmente sua importância; mas mudaria o seu lugar ao deixar de ser o princípio decisivo e tornar-se uma variável dependente no marco de referência moral das respectivas relações de 
reconhecimento. ${ }^{12}$ Com a outra, a concepção intersubjetiva de autonomia, a arquitetura de uma teoria da justiça transforma-se fundamentalmente: não apenas aquilo que pode valer como sua matéria, mas também o seu princípio formal e sua relação com o ator passam por uma nova determinação quando a liberdade individual passa a ser concebida como o resultado de relações de reconhecimento.

A matéria que agora precisa estar em discussão consiste em uma classe especial de relações intersubjetivas, nas quais as cidadãs e os cidadãos concedem-se reciprocamente um status normativo que os habilita para determinadas expectativas; é à luz deste tipo de garantia reciprocamente consentida, de poder esperar um do outro uma determinada consideração, que os sujeitos aprendem a experimentar-se como respeitáveis em perspectivas intersubjetivas, para com isso alcançarem a autonomia. Este tipo de relações de reconhecimento, no entanto, em distinção a bens, não são simplesmente passíveis de ser produzidos socialmente nem podem ser aleatoriamente distribuídos a potenciais beneficiários segundo quaisquer regras; trata-se antes de produtos históricos que assumiram a forma de práticas institucionais nas quais os sujeitos estão incluídos ou das quais podem ser excluídos. O objeto central da teoria que tenho em mente é formado por relações de reconhecimento deste tipo, historicamente sempre já dadas; face a elas, nós não podemos nos colocar no papel de um legislador solitário ou discursivo, mas precisamos primeiro contentar-nos com a perspectiva da tomada de conhecimento e da aceitação. Não obstante, nesse papel altamente restritivo, dispomos do conhecimento de que as relações de reconhecimento que atualmente se descortinam diante de nós já devem sempre pressupor um princípio moral para poder produzir aquilo que é sua função constitutiva em cada caso: pois os sujeitos só podem conceder-se reciprocamente um status normativo, à luz do qual em todos os casos poderão valorizar-se, se para tanto eles conjuntamente fizerem valer um princípio moral que possa servir-lhes como fonte de suas imputações e concessões. Nenhuma relação de reconhecimento, também não aquelas do passado, onde os sujeitos se respeitavam como desiguais, subsiste sem pressupor uma norma aceita reciprocamente; serão sempre estes princípios, conjuntamente tidos como corretos, que devem assegurar que uma práxis do reconhecimento recíproco possa desenvolver-se e perpetuar. Com estes fundamentos normativos de todo

${ }^{12}$ Isto deve significar algo como: que os padrões de medida de uma distribuição justa dos "bens" específicos de cada esfera (no sentido de recursos passíveis de distribuição) resultam dos princípios normativos que determinam em cada caso o tipo de reconhecimento recíproco em tal esfera social. Nessa leitura, sugerida por Anthony Laden em nota acima, também a concepção de "distributive justice" de Rawls deveria ser assim compreendida, apenas que ele não distingue diferentes tipos de relações de reconhecimento, mas apenas aceita a relação igualitária entre cidadãs e cidadãos como relação de reconhecimento prévio. 
reconhecimento, a teoria da justiça aqui visada tem já os primeiros critérios com base nos quais ela poderá julgar as instituições e políticas existentes; pois segundo o que até aqui foi dito, aquilo que aqueles princípios morais exigem em cada caso para uma determinada relação de reconhecimento coincide com as condições nas quais os sujeitos podem conjuntamente alcançar aspectos de sua autoestima. "Justo", por conseguinte, poder-se-ia dizer provisória e ainda desprotegidamente, seria organizar e equipar socialmente uma esfera existente da sociedade de tal maneira como o exige a norma de reconhecimento a ela subjacente (cf. fundamentalmente Honneth, 2003, p. 201ss).

Antes de poder seguir tornando plausível e substancializando a tese assim sugerida, preciso tratar da questão que busca o princípio de justificação que neste contexto efetivamente deve ser aplicado. Havíamos visto que as teorias anteriormente analisadas tentam hipoteticamente justificar os princípios por elas defendidos ao constituírem um procedimento imparcial de discussões, no qual cidadãs e cidadãos teriam chegado a um acordo sobre as respectivas normas. Mas este tipo de procedimentalismo não oferece uma opção viável para a posição que aqui está sendo esboçada, já porque entre suas premissas a matéria da justiça precisa ser pressuposta como historicamente dada; mas onde não podemos mover e distribuir arbitrariamente a matéria de nossas intenções morais, também não vale a pena procurar por princípios hipotéticos pelos quais possamos nos orientar nesse momento. Partir das relações de reconhecimento sempre já existentes, por seu turno, exige que a fundamentação dos princípios de justiça seja feita por uma via que conduza através do material histórico: não podemos mais justificar os respectivos fundamentos na perspectiva de um procedimento constituído, mas precisamos fundamentá-los ao descobrilos nas respectivas relações comunicativas como suas próprias condições de validade. Nesse sentido, o processo que passa a ser aplicado em consequência da nova determinação do objeto pode ser designado como "reconstrutivo": a teoria não "constrói" mais um ponto de vista imparcial, a partir do qual os princípios da justiça possam ser fundamentados, mas os "reconstrói" a partir do processo histórico das relações de reconhecimento, no qual já estão sempre ativos como normas da valorização e consideração recíprocas. ${ }^{13}$ Uma teoria da

${ }^{13}$ Em Facticidade e validade, Habermas (1992, p. 87ss) justifica seu procedimento metodológico de modo similar. A diferença entre o seu e o meu empreendimento no entanto consiste em que ele tão somente quer tomar o desenvolvimento histórico do moderno estado de direito como objeto de uma reconstrução normativa, enquanto eu, face às atribuições de uma teoria da justiça, considero adequado realizar tal reconstrução em toda a amplitude do desenvolvimento de todas as esferas institucionais de reconhecimento centrais para a modernidade. Com isso naturalmente crio para mim o problema de ter que afirmar que todas estas (três) diferentes esferas formam corporificações de princípios de reconhecimento, cuja realização prática por meio de interações fomentam a autonomia individual em forma funcionalmente específica. 
justiça criada assim reconstrutivamente, quando comparada com as propostas procedimentalistas, possui ao mesmo tempo mais confiança e mais ceticismo face à realidade histórica. Mais confiança, porque vê nas próprias relações comunicativas historicamente estabelecidas os princípios normativos sobre os quais exigências de justiça social devem poder se apoiar em vigor; por isso ela pode limitar-se a simplesmente fazer valer explicitamente aqueles princípios pelos quais os sujeitos socializados implicitamente já sempre se orientam em suas relações de reconhecimento. Onde, no entanto, este tipo de pressupostos inexistirem, onde historicamente nos encontramos diante de relações sociais completamente destruídas eticamente e desmoralizadas, lá esta teoria da justiça está relativamente desamparada; também ela terá que recorrer ao abrigo da construção de um ponto de vista imparcial para não perder totalmente de vista os princípios da justiça social. ${ }^{14}$ Mas nas condições de aplicação desta situação de exceção, porém, também está fundamentado por que uma teoria da justiça que procede reconstrutivamente em geral se porta com mais ceticismo que suas alternativas procedimentalistas: pois ela não confia aos processos de formação de consenso ficticiamente criados a capacidade de nos informarem realisticamente sobre os princípios da justiça, porque ela sempre se pergunta se com eles as relações sociais existentes não estariam sobrecarregadas.

Contudo, o ceticismo da teoria da justiça aqui apresentada é mais amplo do que mostrei com esta pequena indicação. Poderia haver a expectativa de que uma teoria assim, no transcurso de sua reconstrução normativa, encontraria como fato histórico justamente aqueles procedimentos discursivos sobre os quais as posições procedimentalistas se fundamentam apenas hipoteticamente; poderíamos então descobrir na realidade social de sociedades modernas uma relação de reconhecimento central, específica, no marco da qual as cidadãs e os cidadãos alcançariam a autonomia individual ao participarem de processos democráticos de formação da opinião e de vontade, e por esta via definiriam em conjunto os princípios da justiça social (Habermas, 1992, cap. 3-4). Em tais circunstâncias, a teoria poderia desfazer-se na tarefa de fixar tais princípios, pois ela tão somente precisaria dissecar e proteger os pressupostos normativos sob os quais os resultados discursivos do procedimento já existente poderiam valer como justificados. O motivo pelo qual sou cético frente a tal tipo de procedimentalismo ${ }^{15}$ resulta do fato de que considero mais e diferentes formas

${ }^{14}$ Esta formulação foi escolhida como paralelo à ideia de Hegel (1970, § 138, acréscimo) de que "ao ponto de vista puramente moral", ou seja, à interioridade da consciência moral, cabe uma tarefa específica legítima sempre quando a realidade social se tornou "desprovida de espírito e postura".

${ }^{15}$ Como uma destas formas de procedimentalismo eu compreenderia a teoria da justiça esboçada por Habermas em Facticidade e validade. 
de reconhecimento social como necessárias para a autonomia individual do que aquelas que podem ser garantidas pela participação em processos públicos de formação da vontade; os sujeitos necessitam da valorização e da consideração intersubjetivas também em papéis sociais que desempenham para além de suas atividades como sujeitos de direito e nos quais estão, por essa razão, juridicamente insuficientemente protegidos por sua própria autolegislação conjuntamente desenvolvida. Com isso, no que segue, retomo o fio condutor de minha argumentação ali onde eu o havia deixado antes de passar a discutir o princípio procedimental da teoria da justiça aqui esboçada.

No que antecedeu, eu reiteradamente apontei que os sujeitos dependem do reconhecimento tanto de suas necessidades como de suas convicções e habilidades para poderem participar autonomamente da vida social; não basta conceber sua autonomia tão somente como resultado do respeito intersubjetivo por sua competência racional de formar juízo e tomar decisão; ao contrário, é necessária adicionalmente uma valorização da natureza particular de suas necessidades e de seu desempenho individual. Somente quando cidadãs e cidadãos puderem saber-se hoje estimados e reconhecidos em todos estes elementos de sua personalidade, eles estarão em condições de se apresentarem publicamente com autoestima e de se empenharem pelas suas respectivas carreiras. Por isso, pois, o processo reconstrutivo que acabo de apresentar como método de justificação desta teoria alternativa da justiça não pode limitar-se a desvendar o princípio de reconhecimento da relação jurídica já estabelecida; enquanto nela os sujeitos se respeitam reciprocamente em sua competência para a formação reflexiva de juízos, subsistem ainda outras relações de reconhecimento, igualmente significativas, que permitem ao indivíduo experimentar ser valorizado também em suas necessidades e habilidades. Se ela efetivamente deve desbravar todas as condições sob as quais os sujeitos hoje podem alcançar a autonomia, a reconstrução normativa deve estar voltada a todo este espectro de relações sociais recíprocas sob as quais os sujeitos hoje podem alcançar a autonomia; ao lado das relações jurídicas, portanto, ao menos as relações familiares íntimas e as relações sociais de trabalho necessitam também ser tomadas como objeto de nossa teoria da justiça. Mesmo que as cidadãs e os cidadãos só possam interferir muito limitadamente nas esferas indicadas através da legislação democrática, também suas condições de reconhecimento se revelam como significativas para as questões de justiça, pelo fato de elas em grande medida corroborarem para o sucesso ou fracasso da autonomia individual.

Do mesmo modo que nas relações jurídicas da democracia no estado de direito, na modernidade dos indivíduos espera-se que também na relação 
interna da família e no intercâmbio social de desempenhos eles se reconheçam reciprocamente como iguais e livres; diferentemente do que em sociedades tradicionais, também estas duas esferas, pouco juridificadas, em princípio devem hoje fazer jus à exigência de assegurar um reconhecimento simétrico e igualitário entre seus membros (Honneth, 2003, cap. 2.1). No entanto, dentro de um processo de reconstrução normativa, se revelará logo que os pontos de vista morais que servem em cada caso como fonte da valorização recíproca são bem distintos: enquanto nas relações jurídicas democráticas é a igualdade deliberativa de todos os sujeitos que forma a base normativa do respeito assegurado entre os participantes, na relação interna da família o são as necessidades particulares de cada um de seus membros e na relação social de trabalho o são os desempenhos individuais dos participantes que servem como pontos de referência do reconhecimento. Com isso, contudo, uma teoria da justiça que procede reconstrutivamente está hoje colocada diante do desafio de defender em nome da autonomia individual não apenas um princípio normativo, mas logo três destes princípios: dependendo da esfera social a que ela se volta, ela deve destacar e fortalecer o ponto de vista moral da igualdade deliberativa, da justiça das necessidades ou da justiça do desempenho. ${ }^{16} \mathrm{Um}$ pluralismo destes, por mais difícil que pareça de manejar, vem ao encontro das diferenciações com as quais os próprios sujeitos operam topicamente em questões da justiça; como revelam hoje uma série de pesquisas empíricas, também eles normalmente distinguem nos problemas ligados à cooperação em seu cotidiano exatamente os três âmbitos mencionados, para aplicar a cada um deles o correspondente princípio de justiça (Miller, 2008, cap. 4).

É esta coincidência empírica que dá à teoria da justiça aqui esboçada a esperança de poder diminuir novamente o abismo em direção à práxis política. Sua tarefa seria colocar diante de nossos olhos todas as condições institucionais, materiais e legais que atualmente precisariam estar cumpridas para que as diferentes esferas sociais efetivamente pudessem fazer jus às normas de reconhecimento a elas subjacentes; com o objetivo de fomentar a autonomia individual, ela não apenas deveria defender em relações jurídicas democráticas o princípio da igualdade deliberativa, em relações familiares o princípio da justiça das necessidades e nas relações sociais de trabalho o princípio da justiça do desempenho, mas exigir também a inclusão de todos os

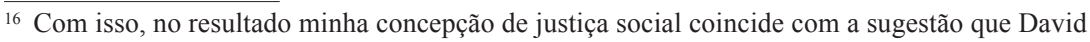
Miller esboçou em sua teoria plural da justiça, ao ter sugerido uma tripartição em princípio da necessidade, ideia de igualdade e princípio do mérito, tendo como base a consideração das convicções cotidianas de justiça (Miller, 2008). Sobre as muitas diferenças que resultam sobretudo do fato de que eu considero que a distinção nestas diferentes "esferas da justiça" necessita uma justificativa de modo "reconstrutivo", cf. Honneth (2008b). 
sujeitos nestas relações de reconhecimento. Assim procedendo, essa teoria da justiça sabe-se em sintonia com as conviç̧ões morais que as pessoas afetadas defendem em seu cotidiano, antes ainda de qualquer teoria; mas por outro lado ela não pode mais fazer a aplicação de seus próprios princípios, nem mesmo suas próprias diferenciações, dependerem do resultado de uma formação democrática da vontade dentre aquelas pessoas afetadas. Pois ela sabe muito bem que estas decisões são apenas provisórias, partidárias e distorcidas até que todas as cidadãs e todos os cidadãos possam levantar sua voz na esfera pública livres de qualquer temor ou vergonha. Devido a este elemento da autonomia individual, por causa desta liberdade elementar do apresentarse e posicionar-se publicamente, a teoria da justiça aqui defendida precisa defender advocatoriamente condições nas quais os sujeitos alcançam autoestima não apenas na esfera pública democrática, mas também em relações familiares e nas relações de trabalho. Na realização destas intenções, porém, ela não pode confiar unicamente nos meios legais do estado de direito, mas precisa apostar na cooperação de organizações não estatais, cujas atividades porém necessitam primeiro novamente do impulso de concepções de justiça ao mesmo tempo mais poderosas e mais realistas, para poderem tornar-se novamente ativas no lugar certo com um vocabulário moral adequado - e pelo menos esta perspectiva poderia nutrir a esperança de que uma teoria da justiça que procede reconstrutivamente e é construída de forma pluralista possa diminuir a distância para com a práxis política.

\section{Referências}

BENSON, Paul. Taking ownership: authority and voice in autonomous agency. In: CHRISTMAN, John; ANDERSON, Joel (Orgs.). Autonomy and the challenges to liberalism: new essays. Cambridge: Cambridge University Press, 2005. p. 101-126.

DOPPELT, Gerald. Rawls's system of justice: a critique from the left. Noûs, v. 15, p. 259-307, 1981.

DURKHEIM, Emile. Physik der Sitten und des Rechts. Frankfurt am Main: Suhrkamp, 1999.

ETZIONI,Amitai.DieEntdeckungdes Gemeinwesens:Ansprüche, Verantwortlichkeiten und das Programm des Kommunitarismus. Frankfurt am Main: Fischer, 1998 [1993].

HABERMAS, Jürgen. Faktizität und Geltung: Beiträge zur Diskurstheorie des Rechts und des demokratischen Rechtsstaats. Frankfurt am Main: Suhrkamp, 1992

. Versöhnung durch öffentlichen Vernunftgebrauch. In: Die Einbeziehung des Anderen: Studien zur politischen Theorie. Frankfurt am Main: Suhrkamp, 1996. p. 65-94.

HAHN, Henning. Moralische Selbstachtung. Berlink: Walter de Gruyter, 2008. 
HEGEL, Georg W. F. Grundlinien der Philosophie des Rechts. In: MOLDENHAUER, Eva; MICHEL, Karl Markus (Orgs.). Werke in zwanzig Bänden, Theorie-Werkausgabe. Frankfurt am Main: Suhrkamp, 1970 (1821). v. 7.

HONNETH, Axel. Kampf um Anerkennung: Zur moralischen Grammatik sozialer Konflikte. Frankfurt am Main: Suhrkamp, 1992a.

. (Org.). Kommunitarismus: Eine Debatte über die moralischen Grundlagen moderner Gesellschaften. Frankfurt am Main: Campus, 1992b.

. Zwischen Gerechtigkeit und affektiver Bindung. Die Familie im Brennpunkt moralischer Kontroversen. In: . Das Andere der Gerechtigkeit. Aufsätze zur praktischen Philosophie. Frankfurt am Main: Suhrkamp, 2000. p. 193-215.

. Umverteilung als Anerkennung. Eine Erwiderung auf Nancy Fraser. In: FRASER, Nancy; HONNETH, Axel. Umverteilung oder Anerkennung? Eine politischphilosophische Kontroverse. Frankfurt am Main: Suhrkamp, 2003. p. 129-224.

. Arbeit und Anerkennung: Versuch einer Neubestimmung, Deutsche Zeitschrift für Philosophie, v. 56, n. 3, p. 327-341, 2008. [Trabalho e reconhecimento: tentativa de uma redefinição. Civitas, v. 9, n. 1, p. 46-67, jan.-abr. 2008.].

. Philosophie als Sozialforschung. Die Gerechtigkeitstheorie von David Miller. In: MILLER, David. Grundsätze sozialer Gerechtigkeit. Frankfurt am Main: Campus, 2008b, p. 7-25.

LADWIG, Bernd. Freiheit. In: GÖHLER, Gerhard; ISER, Matthias; KERNER, Ina (Orgs.). Politische Theorie: 22 umkämpfte Begriffe zur Einführung. Wiesbaden: VS Verlag für Sozialwissenschaften, 2004. p. 83-100.

MACKENZIE, Catriona; STOLJAR, Natalie (Orgs.). Relational autonomy: feminist perspectives on autonomy, agency, and the social self. New York: Oxford University Press, 2000.

MEYERS, Diana T. Work and self-respect. In: EZORSKY, Gertrude (Org.). Moral rights in the workplace. Albany: State University of New York Press, 1987. p. 18-27. 1989.

. Self, society, and personal choice. New York: Columbia University Press,

MILLER, David. Grundsätze sozialer Gerechtigkeit. Frankfurt am Main: Campus, 2008 (1999).

NAGEL, Thomas. The problem of global justice. In: Philosophy and Public Affairs. 2005. v. 33, p. 113-147.

NEUHOUSER, Frederick. Rousseau's theodicy of self-love: evil, rationality, and the drive for recognition. New York: Oxford University Press, 2008.

RAWLS, John. Eine Theorie der Gerechtigkeit. Frankfurt am Main: Suhrkamp, 1979 (1971).

. Politischer Liberalismus. Frankfurt am Main: Suhrkamp, 1998 (1993).

RAZ, Joseph. The morality of freedom. Oxford: Clarendon, 1986.

SANDEL, Michael J. Liberalism and the limits of justice. Cambridge: Cambridge University Press, 1982. 
SCHELER, Max. Der Formalismus in der Ethik und die materiale Wertethik. Bern: Francke Verlag, 1966 (1916).

SCHMIDT am BUSCH, Hans-Christoph. Hegels Begriff der Arbeit. Berlin: Akademie Verlag, 2002.

TAYLOR, Charles. The diversity of goods. In: . Philosophy and the Human Sciences. Philosophical Papers 2. Cambridge: Cambridge University Press, 1985. p. 230-247.

. Negative Freiheit? Zur Kritik des neuzeitlichen Individualismus. Frankfurt am Main: Suhrkamp, 1988.

WELLMER, Albrecht. Freiheitsmodelle in der modernen Welt. In: . Endspiele: Die unversöhnliche Moderne. Frankfurt am Main: Suhrkamp, 1993. p. 15-53.

YOUNG, Iris Marion. Justice and the politics of difference. Princeton: Princeton University Press, 1990.

ZAHLMANN, Christel (Org.). Kommunitarismus in der Diskussion: Eine streitbare Einführung. Berlin: Rotbuch-Verlag, 1992. 